\title{
Commentary: "My Husband Affects Me More Than My Cancer": Reflections on Simultaneous Intimate Partner Violence and Breast Cancer Experience in a 48-Year-Old Woman
}

Francesca Dionigi 1,2*, Valentina Martinelli ${ }^{3}$, Eugenia Trotti3 ${ }^{3}$, Alberta Ferrari ${ }^{2,5}$, Carlos Alberto Garcia Etienne ${ }^{2}$, Angelica Della Valle ${ }^{2}$, Donatella Grasso ${ }^{6}$, Elisa Ferraris ${ }^{6}$, Gianpiero Rizzo ${ }^{6}$,Angioletta Lasagna ${ }^{6}$, Vincenza Praticò ${ }^{2}$, Paolo Pedrazzoli,Pierluigi Politi ${ }^{6}$, Adele Sgarella ${ }^{2,5}$

'Dottorato di Ricerca in Medicina Sperimentale, Università degli Studi di Pavia, 27100, Pavia, Italy

2Fondazione IRCCS Policlinico "San Matteo", Unità Operativa Complessa di Chirurgia Generale III a indirizzo Senologico e dei tessuti molli, viale Golgi 19, 27100, Pavia, Italy

${ }^{3}$ Dipartimento di Medicina e Sanità Pubblica, Università dell'Insubria, via Ottorino Rossi 9, 21010 Varese, Italy ${ }^{4}$ Department of Biotechnology and Life Sciences, Università degli Studi dell'Insubria, via Ottorino Rossi 9, 21010, Varese, Italy "Università degli Studi di Pavia, Pavia, Italy

${ }^{6}$ Fondazione IRCCS Policlinico "San Matteo", Unità Operativa Complessa di Oncologia Medica, Pavia, Italy

\section{Article Info}

\section{Article Notes}

Received:April 27, 2020

Accepted: June 26, 2020

\section{*Correspondence:}

Dr. Francesca Dionigi, Dottorato di Ricerca in Medicina Sperimentale, Università degli Studi di Pavia, 27100, Pavia, Italy; Email: francesca.dionigi@unipv.it .

(c) 2020 Diongi F. This article is distributed under the terms of the Creative Commons Attribution 4.0 International License.

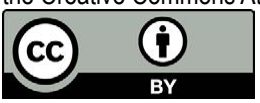

\section{Keywords:}

Breast Cancer

Intimate Partner Violence

Breast Reconstruction

Early Childhood Abuse

\section{ABSTRACT}

We present our commentary about the case of a 48-year-old woman diagnosed with early breast cancer, already presented as publication. A candidate for mastectomy, she refused immediate reconstruction. She was referred to a psycho-oncologist for further evaluation and support. Psychological sessions helped reveal a history of intimate partner violence and helped clarify the reason for her refusal to undergo immediate reconstruction and other uncommon behavior about oncological treatment and disease paths. Our experience highlights the importance of a multidisciplinary practice in which collaboration between surgeons, oncologists, and mental health professionals leads to a more in-depth understanding of the apparently paradoxical behaviors of patients, and to better care for their needs.

Violence against women is a worldwide public problem ${ }^{1,2}$ nowadays. According to the World Health Organization its prevalence in 79 countries is over $30 \%{ }^{1,3}$. Women are generally exposed to a variety of male violence, particularly husband or lover violence ${ }^{1}$. In Europe approximately one woman out of three ${ }^{4,5}$ experiences intimate partner violence (IPV).

Breast cancer (BC) is one of the most important female public health problems in Western Countries. BC is a multidimensional disease that affects women physically, psychologically and socially ${ }^{1}$. In Europe one woman out of eight develops BC during her lifetime. The number of women who will simultaneously experience BC and IPV is still unknown ${ }^{1,5}$, but we could hypothesize that its prevalence is relatively high ${ }^{1}$.

Literature describes both the direct and indirect impact of a violence experience on the $\mathrm{BC}$ process. Sexual, physical and psychological violence could worsen BC care paths, delay screening and/or diagnosis, decrease quality of life over the disease period and worsen survival ${ }^{1}$.

Research has observed that women's psychological and mental problems related to a violence experience have a strong impact on cancer diagnosis and/or treatment. Women develop psychological 
and behavioral alterations over the diagnostic and therapeutic process ${ }^{1,6,7}$; showing higher distress and depression scores ${ }^{1,8}$. IPV and abuse in childhood (CA) correlate with cancer-related psychological problems such as feeling more tired and having lower specific physical and emotional welfare ${ }^{1,9}$. Finally, violence is a risk factor for the development of emotional problems after BC surgery ${ }^{1,10}$.

However the number of studies on this subject is limited $^{1,5}$. The relationship among IPV, CA, other violence related symptoms and $\mathrm{BC}$ needs to be investigated in detail $^{1,8}$. The psychological reasons at the origin of abused women's behavioral alterations in coping the $\mathrm{BC}$ experience are still not clear. The role of the personal illness in the marital relationship and the strategies that women adopt to cope with their body changes are also still not clear.

Our manuscript describes an example of a personal strategy adopted by a dependent and abused woman in dealing with a life-threatening disease, and highlights how the experience of body loss in BC could be based on personal perceptions of her own breast and, more broadly, of self-identity and self-awareness. The article furthermore shows the influence of a woman's personal history of fragility on IPV and on her cancer care continuum ${ }^{10}$.

We reported the case of a 48-year-old, highly educated, middle class woman, who showed contradictory attitudes and behavior during her diagnostic and therapeutic BC sessions. At the first surgical visit she adamantly refused the proposal of breast reconstruction, during her chemotherapy treatment she asked her oncologist to refrain from giving any good news to her husband. In the presence of health staff she never showed anxiety or signs of depressed mood about her cancer or chemotherapy side effects. When she received the bad news of a diagnosis of lymph node metastasis, she seemed to neglect her disease and never complained of fear or angst.

At the same time the patient was compliant with her physicians' indications, during all of the stages of medical intervention. She never complained about chemotherapy side effects: body changes did not seem to be really a problem for her.

From her instances of contradictory behavior between her compliance to treatment and her apparent emotional denial of good and bad news, the medical staff suspected unspoken needs and asked for a psycho-oncological intervention. After more than one meeting with the psychooncologist, the patient revealed to be victim of IPV: that she had been living a marital relationship characterized by violence for more than 20 years. The IPV consisted of psychological aggression and physical abuse against her and her six children. They had been referred to the Accident and Emergency Department after more than one serious knife-throwing assault. A psychiatric evaluation was set up, and antidepressants were prescribed. During the following four years of her BC diagnosis, through the psycho-oncological support, she was able to recognize her IPV problems and to identify her major life events that brought her to choose a violent partner. An effect of her psychotherapeutic process enabled her to remember an early CA. She started to recognize her personal reality and gradually became more self-aware of her feelings and needs. As a result of this process, she began to wonder about her cancer disease evolution and to feel angst: she stopped using her disease as a protection.

This case showed us how specific mental mechanisms of abused women could condition their cancer care. Differently from other studies, this woman did not refuse the cancer diagnosis or decided to abandon her treatment, despite their invasiveness and severe consequences on family daily routines ${ }^{11}$. Similarly, her partner, who often accompanied her to the hospital, did not show denial behavior: he seemed to share in her cancer care and to support her physical needs ${ }^{11}$. How did she use her own disease and sick body in a couple relationship characterized by IPV? The patient had been asking physicians not to eradicate the signs of cancer from her body, but to make those signs on her body as evident as possible: she wanted to project a poor body image and exhibit her body cancer signs to appear ill. This seemed to be her strategy to manage her submissive relationship with her husband. She asked her physicians to be complicit in disclosing her mutilated body and physical damage, as a consequence of her identification into the pattern of the sick role ("I am my sick body") and to keep her violent husband "in check".

Moreover in this case we observed the clinical depression $^{1,5}$ arising from feelings of self-deprecation previous to the IPV experience. In literature we think that this subject is not always fully discussed. Our patient showed us that the psychological reasons of her affective dependence should be placed in her early CA history ${ }^{12,13}$, that substantially impacted on her self-identity ${ }^{5}$ and self-awareness of her feelings and needs. In our clinical experience a diagnosis of BC could often disclose patient's mental health vulnerability ${ }^{10}$. In our experience, this condition of mental fragility could obstacle dependent women to cope with the cancer disease experience ("My husband affects me more than my cancer") ${ }^{1,5,10,14}$ and could reduce the patient's chances of seeking for support, particularly from medical staff ${ }^{1,5,15}$.

The case evolution confirmed the necessity of a multidisciplinary intervention. Our group started a long term care plan for this patient which enabled her eventually to request help. A constant discussion among the surgeon, the oncologist, the psycho-oncologist, the breast nurse and the psychiatrist was necessary in order to uncover the violence on the patient, evidently considered a "taboo" for her ${ }^{1,12}$. 
Our findings also support the need to reinforce programs that bring attention to the multi-disciplinary care plan, understanding patients' needs and management of their distress factors ${ }^{5,16}$.

In this commentary we would also highlight the importance of a real multi-disciplinary practice. As confirmed, $\mathrm{BC}$ requires a much broader perspective than that of a solely body/physical approach ${ }^{5,16}$ Moreover integrated and individualized team interventions could really understand the emotional functioning of each woman in dealing with her BC experience during every step of the diagnostic and treatment process.

In conclusion we would suggest the importance of preliminary evaluations, already during diagnostic set, especially in those situations where patient decisions seem to contrast with good clinical practice and also with good common sense ${ }^{5}$. Collaboration between surgeons, oncologists, breast nurses and mental health professionals leads to a more in-depth understanding of the apparently paradoxical behavior of patients, and better care of their needs ${ }^{5}$ during all the treatment process.

Finally, in this age of personalized medicine, the inclusion of psycho-oncological treatment as a complementary medical care treatment, that is customized for an individual patient, should become more commonly adopted ${ }^{5}$.

\section{References}

1. Aygin D, Bozdemir H. Exposure to violence in breast cancer patients: systematic review. Breast Cancer. 2019 Jan; 26(1): 29-38. doi: 10.1007/s12282-018-0900-6.

2. Brown MJ, Weitzen S, Lapane KL. Association Between Intimate Partner Violence and Preventive Screening Among Women. J Womens Health (Larchmt). 2013 Nov; 22(11): 947-52. doi: 10.1089/ jwh.2012.4222.

3. WHO. Global and regional estimates of violence against women: prevalence and health effects of intimate partner violence and non-partner sexual assault. 2013. http://apps.who.int/iris/ bitstream/10665/85239/1/9789241564625\$4eng.pdf?ua=1. Accessed 14 June 2017.

4. United Nations Department of Economic and Social Affairs Sustainable Development Goals Overview. Goal No. 5. https://unstats.un.org/ sdgs/report/2017/goal-05/ Accessed 9 September 2019.
5. Dionigi F, Martinelli V, Trotti E, et al. "My Husband Affects Me More Than My Cancer": Reflections on Simultaneous Intimate Partner Violence and Breast Cancer Experience in a 48-Year-Old Woman. J Cancer Educ. 2019 Nov 30. doi: 10.1007/s13187-019-01661-9.

6. Johnson WA, Pieters HC. Intimate partner violence among women diagnosed with cancer. Cancer Nurs TM. 2016; 39(2): 87. https://doi. org/10.1097/NCC.0000000000000265.23

7. Izci F, Ilgun AS, Findıklı E, Ozmen V. Psychiatric symptoms and psychosocial problems in patients with breast cancer. J Breast Health. 2016; 12: 94-101. https://doi.org/10.5152/tjbh.2016.3041.

8. Coker A, Follingstad D, Garcia LS, et al. Association of intimate partner violence and childhood sexual abuse with cancer-related wellbeing in women. J Women's Health. 2012. https://doi.org/10.1089/ jwh.2012.3708.17

9. Salmon P, Hill J, Krespi R, et al. The role of child abuse and age in vulnerability to emotional problems after surgery for breast cancer. Eur J Cancer. 2006; 42: 2517-2523. https://doi.org/10.1016/j. ejca.2006.05.024.

10. Dionigi F, Ferrari A, Pratico, V,et al. Ostacoli nel processo decisionale di una paziente BRCA1 positiva con carcinoma mammario. Il trattamento in Equipe multidisciplinare, il ruolo dello psico-oncologo. Journal of Psychosocial Systems. 2019; 3(2): 66-74. https://doi.org/10.23823/ jps.v3i2.61

11. Martino MA, Balar A, Cragun JM, et al. Delay in treatment of invasive cervical cancer due to intimate partner violence. Gynecol Oncol. 2005; 99 (2): 507-509doi:10.1016/j.ygyno.2005.06.034

12. Clark L, Holcombe C, Hill J, et al. Sexual abuse in childhood and postoperative depression in women with breast cancer who opt for immediate reconstruction after mastectomy. Ann R Coll Surg Engl. 2011 Mar; 93(2): 106-110. doi: 10.1308/003588411X1285163910 7593

13. McFarland DC, Andreotti C, Harris K, et al. Early Childhood Aversity and its Associations With Anxiety, Depression, and Distress in Women With Breast Cancer. Psychosomatics. 2016 Mar-Apr; 57(2): 174-184. doi: 10.1016/j.psym.2015.11.008

14. Sawin EM, Laughon K, Parker BJ, et al. Breast cancer in the context of intimate partner violence: a qualitative study. Oncol Nurs Forum. 2009; 36 (6): 686-692. doi:10.1188/09.0nf.686-692.

15. Salmon P, Holcombe C, Clark L, et al. Relationships with clinical staff after a diagnosis of breast cancer are associated with patients' experience of care and abuse in childhood. J Psychosom Res. 2007; 63: 255-62. htpps://doi.org/10.1188/09.0NF.686-692.

16. Dionigi F, Milani R, Garcia-Etienne CA, et al. The institution of a Multidisciplinary Italian Breast Unit: Reflections of the first psychosocial research study results on distress and quality of life. Breast J. $2019 \mathrm{Jul}$; 25(4): 678-681. doi: 10.1111/tbj.13244. 